University of Nebraska - Lincoln

DigitalCommons@University of Nebraska - Lincoln

\title{
Identifying grasslands suitable for cellulosic feedstock crops in the Greater Platte River Basin: dynamic modeling of ecosystem performance with $250 \mathrm{~m}$ eMODIS
}

\author{
Yingxin $\mathrm{Gu}$ \\ yingxin.gu.ctr@usgs.gov \\ Stephen P. Boyte \\ Stinger Ghaffarian Technologies, Inc \\ Bruce K. Wylie \\ USGS EROS, wylie@usgs.gov \\ Larry L. Tieszen \\ USGSEROS, tieszen@usgs.gov
}

Contractor to US Geological Survey (USGS) Earth Resources Observation and Science (EROS) Center,

Follow this and additional works at: https://digitalcommons.unl.edu/usgsstaffpub

Gu, Yingxin; Boyte, Stephen P.; Wylie, Bruce K.; and Tieszen, Larry L., "Identifying grasslands suitable for cellulosic feedstock crops in the Greater Platte River Basin: dynamic modeling of ecosystem performance with 250 m eMODIS" (2012). USGS Staff -- Published Research. 586.

https://digitalcommons.unl.edu/usgsstaffpub/586

This Article is brought to you for free and open access by the US Geological Survey at DigitalCommons@University of Nebraska - Lincoln. It has been accepted for inclusion in USGS Staff -- Published Research by an authorized administrator of DigitalCommons@University of Nebraska - Lincoln. 


\title{
Identifying grasslands suitable for cellulosic feedstock crops in the Greater Platte River Basin: dynamic modeling of ecosystem performance with $250 \mathrm{~m}$ eMODIS
}

\author{
YINGXIN GU*, STEPHEN P. BOYTE†, BRUCE K. WYLIE $\$$ and LARRYL. TIESZEN \\ *ASRC Research \& Technology Solutions, Contractor to US Geological Survey (USGS) Earth Resources Observation and Science \\ (EROS) Center, Sioux Falls, SD, 57198, USA, †Stinger Ghaffarian Technologies, Inc, Contractor to USGS EROS, Sioux Falls, \\ SD, 57198, USA, †USGS EROS, Sioux Falls, SD, 57198, USA
}

\begin{abstract}
This study dynamically monitors ecosystem performance (EP) to identify grasslands potentially suitable for cellulosic feedstock crops (e.g., switchgrass) within the Greater Platte River Basin (GPRB). We computed grassland site potential and EP anomalies using 9-year (2000-2008) time series of $250 \mathrm{~m}$ expedited moderate resolution imaging spectroradiometer Normalized Difference Vegetation Index data, geophysical and biophysical data, weather and climate data, and EP models. We hypothesize that areas with fairly consistent high grassland productivity (i.e., high grassland site potential) in fair to good range condition (i.e., persistent ecosystem overperformance or normal performance, indicating a lack of severe ecological disturbance) are potentially suitable for cellulosic feedstock crop development. Unproductive (i.e., low grassland site potential) or degraded grasslands (i.e., persistent ecosystem underperformance with poor range condition) are not appropriate for cellulosic feedstock development. Grassland pixels with high or moderate ecosystem site potential and with more than 7 years ecosystem normal performance or overperformance during 2000-2008 are identified as possible regions for future cellulosic feedstock crop development (ca. $68000 \mathrm{~km}^{2}$ within the GPRB, mostly in the eastern areas). Long-term climate conditions, elevation, soil organic carbon, and yearly seasonal precipitation and temperature are important performance variables to determine the suitable areas in this study. The final map delineating the suitable areas within the GPRB provides a new monitoring and modeling approach that can contribute to decision support tools to help land managers and decision makers make optimal land use decisions regarding cellulosic feedstock crop development and sustainability.
\end{abstract}

Keywords: cellulosic biofuel, cellulosic feedstock crops, ecosystem performance models, eMODIS NDVI, Greater Platte River Basin, land management, satellite remote sensing, weather data

Received 7 February 2011; revised version received 25 April 2011 and accepted 26 May 2011

\section{Introduction}

Biofuels are renewable fuels used extensively for motor vehicles, and their use may grow significantly as the world decreases its dependence on fossil fuels (Simpson, 2009; Schnepf \& Yacobucci, 2010). Currently, corn (Zea mays) from the Midwest is used to produce ethanol, the most common biofuel product in the United States (Solomon et al., 2007; Schnepf \& Yacobucci, 2010). Corn-based

Correspondence: Yingxin Gu, tel. +1 605594 6576,

fax +1 605594 6529, e-mail: ygu@usgs.gov ethanol development is limited because of concerns about world food shortages, livestock and food price increases, and negative environmental effects (e.g., water quality impairment due to the greater usage of pesticide and fertilizer, more demand for water for irrigation, and soil erosion) (Trostle, 2008; Gelfand et al., 2010; Pala, 2010; Pimentel, 2010; Schnepf \& Yacobucci, 2010). As a result, policy makers may mandate using cellulosic biofuels produced from grasses, forest woody biomass, and agricultural and municipal wastes in the near future. If this occurs, production of cellulosic feedstocks will dramatically increase (Bracmort, 2010; Bracmort et al., 2010; 
Schnepf \& Yacobucci, 2010). Switchgrass (Panicum virgatum) is being evaluated as one potential source for cellulosic feedstock (Mclaughlin \& Kszos, 2005; Liebig, 2006; Sanderson et al., 2006; Schmer et al., 2008; Bracmort, 2010; Bracmort et al., 2010). Several studies have been conducted regarding the environmental effects of using switchgrass for cellulosic feedstock (Liebig et al., 2008; Schmer et al., 2008, 2010; Vadas et al., 2008; Blanco-Canqui, 2010; Guretzky et al., 2011).

Ecosystem performance (EP) (i.e., a surrogate for approximating ecosystem productivity) provides important information to decision makers for land management. Ecosystem performance is usually affected by site condition (e.g., drainage, elevation, slope, aspect, soils, and surface geology) (Viereck et al., 1984, 1992; Saxon et al., 2005; White et al., 2005), climate (e.g., precipitation and surface temperature) (Rupp et al., 2000; Bunn et al., 2005; Kang et al., 2006; Kimball et al., 2006; Dunn et al., 2007), natural disturbances (e.g., wildfires and floods) (Kang et al., 2006), and management activities (e.g., irrigation and heavy grazing) (Asner et al., 2004; Launchbaugh et al., 2008). Recently, satellite remote sensing has become an essential tool for measuring and monitoring EP over large areas because of its wide coverage and high spatial and temporal resolutions (Wylie et al., 2008; Zhang et al., 2010). Previous studies have shown a strong relationship between satellite vegetation index and biomass productivities (Tucker et al., 1985; Hobbs, 1995; Tieszen et al., 1997; Wang et al., 2005; Gitelson et al., 2006; Funk \& Budde, 2009; Becker-Reshef et al., 2010). The growing season integrated Normalized Difference Vegetation Index (NDVI) derived from satellite observations has been used as a proxy for EP (Tieszen et al., 1997). Interpreting EP variation or ecological disturbance is complex because of the influences of weather, natural disturbances, and management activities. Wylie et al. (2008) developed an approach that separated weather-related (e.g., drought) and ecological disturbance-related (e.g., wildfires, insects, and overgrazing) annual EP variations using the archival record of satellite-derived NDVI data, weather and climate data, geophysical and biophysical data, and EP models. This method provides historical trends for both weather- and disturbance-related EP variations, which helps identify the potential causes of ecosystem variations and can help guide best management practices.

The objective of this study is to implement the dynamic monitoring of EP (Wylie et al., 2008; Gu \& Wylie, 2010) for grasslands in the Great Plains to identify lands potentially suitable for cellulosic feedstock (e. g., switchgrass) development. Our pilot study area is the Greater Platte River Basin (GPRB). We chose the GPRB because it includes a broad range of plant productivities, from semiarid grasslands in the west to the fertile corn belt in the east. The GPRB was also the subject of related integrated research projects. We used $250 \mathrm{~m}$ expedited moderate resolution imaging spectroradiometer (eMODIS) time series NDVI data and weather, climate, biophysical, and geophysical data to build EP models. Results from this study will provide useful information to land managers and decision makers to make optimal land use decisions for cellulosic feedstock development and sustainability.

\section{Materials and methods}

\section{Study area}

Our study area is the GPRB, which is formed by the Platte River Basin, the Niobrara River Basin, and the Republican River Basin, and located in the heartland of the United States. The GPRB covers parts of Wyoming, Colorado, South Dakota, Kansas, and most of Nebraska (Fig. 1). The main vegetation cover types are grassland (ca. 50\%) and cultivated crops (ca. 30\%). More than $60 \%$ of the grasslands are dominated by warm season $\left(C_{4}\right)$ grasses. Other land cover types include shrubs, evergreen and deciduous forests, and pasture/hay (Fig. 1). Annual precipitation in the GPRB increases from west to east. The long-term (1971-2000) precipitation, maximum temperature, and minimum temperature maps are shown in Fig. 2.

\section{Basic concepts of the ecosystem performance study}

For moisture-limited rangelands, the interannual variation in vegetation productivity is significantly related to local weather and climate conditions, management practices, and ecological disturbances. Herein, we define ecosystem site potential as the long-term rangeland productivity (i.e., long-term EP) that averages out climatic variations in weather but accounts for spatial variation in long-term EP associated with site conditions such as drainage, elevation, slope, aspect, soils, climate, and surface geology. Ecosystem site potential does not include ecological disturbance effects (e.g., wildfires, floods, insects, and overgrazing). Highly productive sites will have higher ecosystem site potential than sites with poorer soils, steeper slopes, or other conditions not conducive to vegetation growth. We used satellite-derived growing season integrated NDVI (GSN) as a proxy for the actual EP (Tieszen et al., 1997). We defined the expected EP (EEP) as the expected GSN in a particular year based on the weather conditions of that year (i.e., given the weather conditions of that year and in the absence of disturbance). Favorable weather years will experience higher EEP than years with unfavorable conditions (e.g., too hot or too cold, too wet or too dry) 


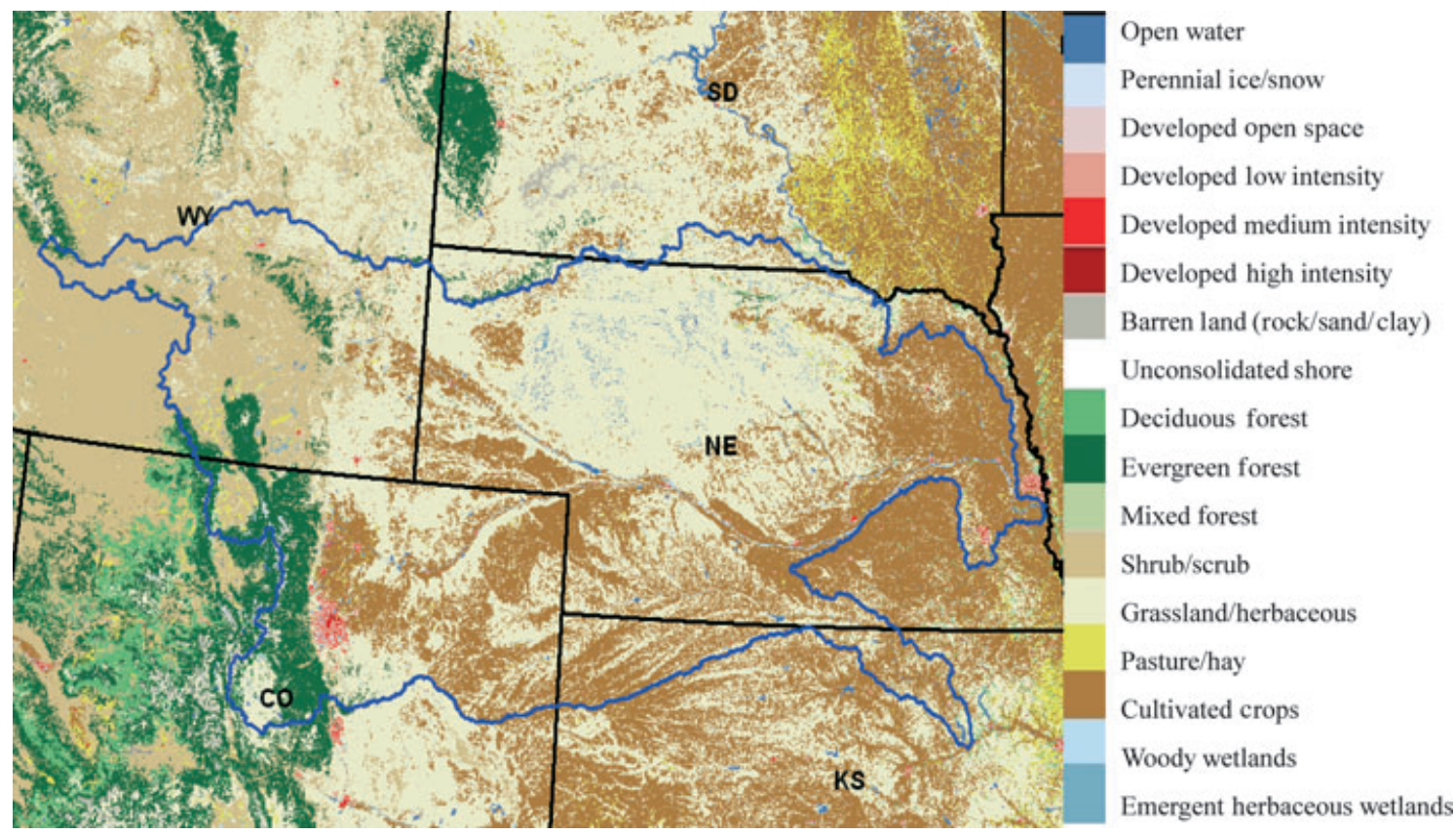

Fig. 1 Location of the Greater Platte River Basin (inside the blue outline) and the land cover types as identified in the NLCD.

(a)

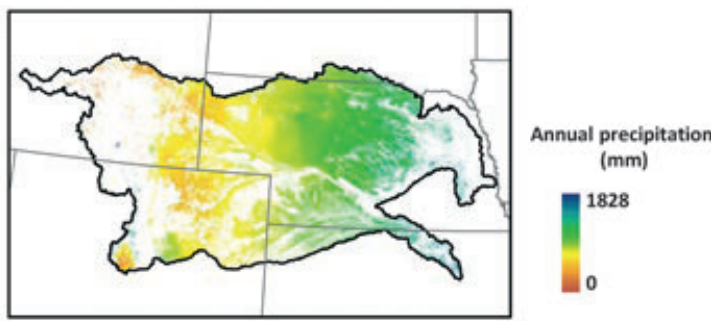

(b)

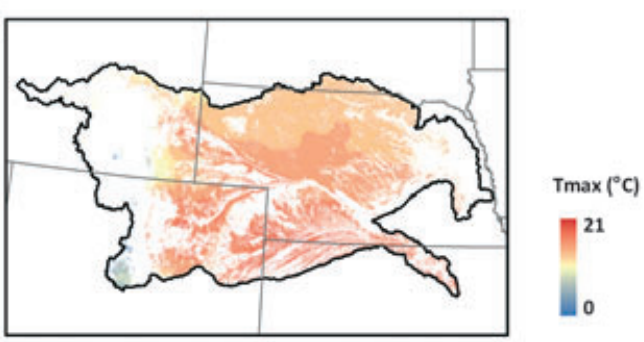

(c)

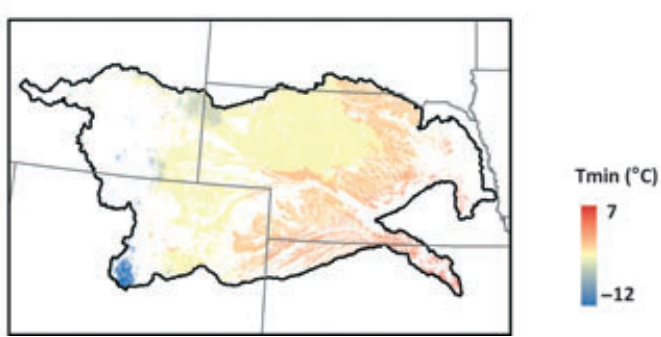

Fig. 2 Climate condition maps for the grassland areas in the GPRB (250 m spatial resolution). (a) 1970-2000 averaged annual precipitation; (b) 1970-2000 averaged maximum temperature; (c) 1970-2000 averaged minimum temperature.
The EP anomaly (EPA) for a year was calculated as the difference between the actual EP and the weather-based EEP, and this difference was categorized as normal performance, underperformance, and overperformance based on the calculated $90 \%$ level of confidence interval. Natural disturbances (e.g., wildfires, floods, and insects) and inappropriate management decisions (e.g., heavy grazing) usually cause significant negative EPAs. Management treatments (e.g., irrigation, fertilization) usually cause positive EPAs. Multiyear EPA maps were used to identify long-term persistent EP anomalies. Table 1 is a brief summary and explanation of the ecological variables used in this study.

Approach and strategy for identifying grasslands potentially suitable for cellulosic feedstock development

In this study, we hypothesize that grassland areas with (i) fairly consistent high grassland productivity (i.e., high ecosystem site potential) and (ii) fair to good range condition (persistent ecosystem normal performance or overperformance, implying a lack of severe ecological disturbance) are potentially suitable for cellulosic feedstock [e.g., switchgrass or Miscanthus (Miscanthus $x$ giganteus)] development.

Historically, many areas of productive grasslands were converted to cropland. Criteria for sites suitable for cellulosic feedstock production may be similar to the criteria that farmers implicitly used historically to select 
Table 1 Summary of ecosystem performance variables used in this study

\begin{tabular}{lll}
\hline Name & Short name & Description \\
\hline Ecosystem site potential & Site potential & Long-term ecosystem productivity \\
Ecosystem performance & EP & Growing season NDVI (GSN) derived from satellite observations \\
Expected ecosystem performance & EEP & Weather-based expected GSN \\
Ecosystem performance anomaly & EPA & The difference between the actual EP and the EEP \\
\hline
\end{tabular}

sites for crops (i.e., select productive grasslands). Therefore, highly productive sites (i.e., sites with high ecosystem site potential) are potentially more suitable for cellulosic feedstock development than sites with poorer soils, steeper slopes, or other conditions not conducive to vegetation growth and harvesting.

Areas with ecosystem overperformance (or normal performance) usually represent good and healthy vegetation conditions with higher grassland productivity than the weather-based EEP; therefore, these regions are potentially suitable for cellulosic feedstock development. On the other hand, areas with ecosystem underperformance usually represent degrading or degraded vegetation conditions or perturbations (i.e., unfavorable vegetation growth conditions caused by wildfire, floods, insects, overgrazing, etc.) with low grassland productivities. We assume these areas are not suitable for cellulosic feedstock expansion because the productivity would be low and the environmental impacts would be high. Here, areas that are vulnerable to disturbance (i.e., sensitive to environmental change) are also not considered suitable for cellulosic feedstock development.
Verification of GSN as a proxy for ecosystem productivity

In this study, GSN was used as the actual EP. To verify and confirm this approach, we assessed the important features in the relationship between eMODIS GSN and the flux tower gross primary productivity (GPP) in the GPRB. Yearly growing season averaged GPP data (during 2000-2002 and 2005-2007) were collected from seven flux towers on grasslands around the GPRB region. The locations and the names of the seven flux towers are shown in Fig. 3. Yearly GSN data were also extracted for each $250 \mathrm{~m}$ pixel that geographically corresponded to each flux tower site. We computed the correlation between eMODIS GSN and the flux tower GPP around the GPRB.

Data and procedures for mapping areas of potential cellulosic feedstock expansion

Figure 4 is a flowchart illustrating how our EP anomalies were calculated and how the target areas (areas suitable for cellulosic feedstock expansion) were identified. More detailed data processing steps included:

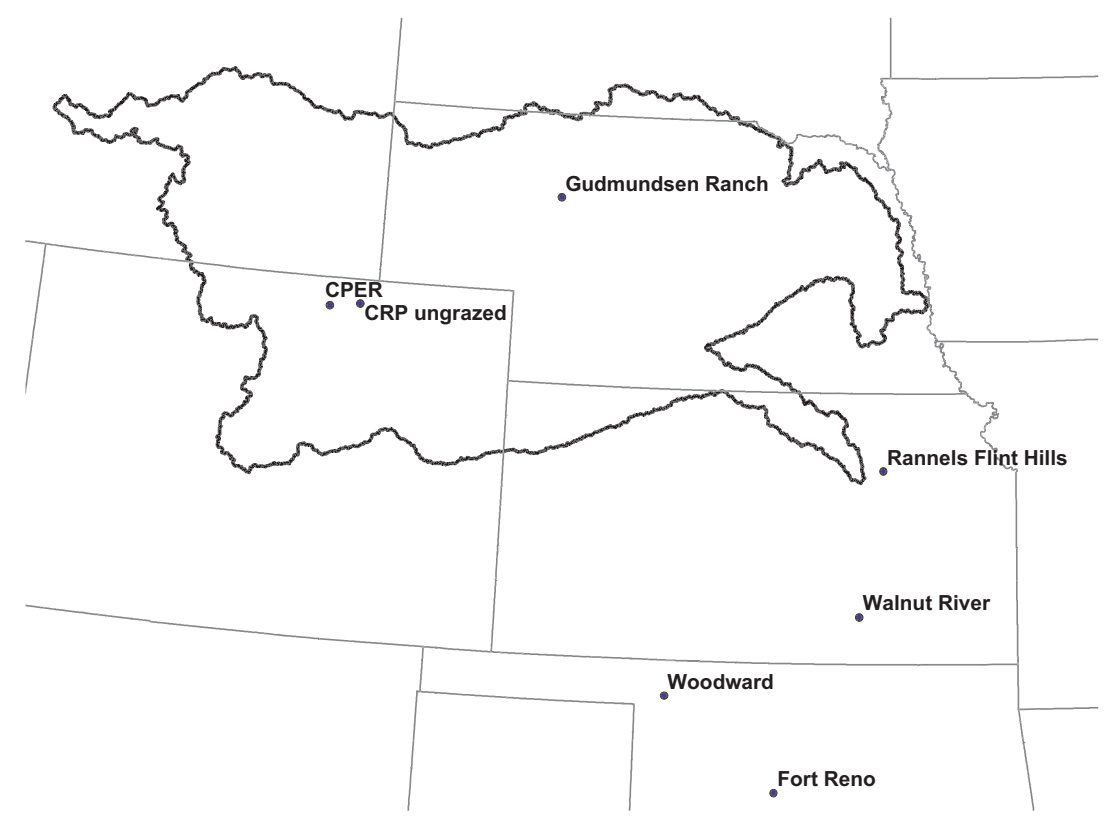

Fig. 3 Locations of the seven flux towers around the GPRB. 


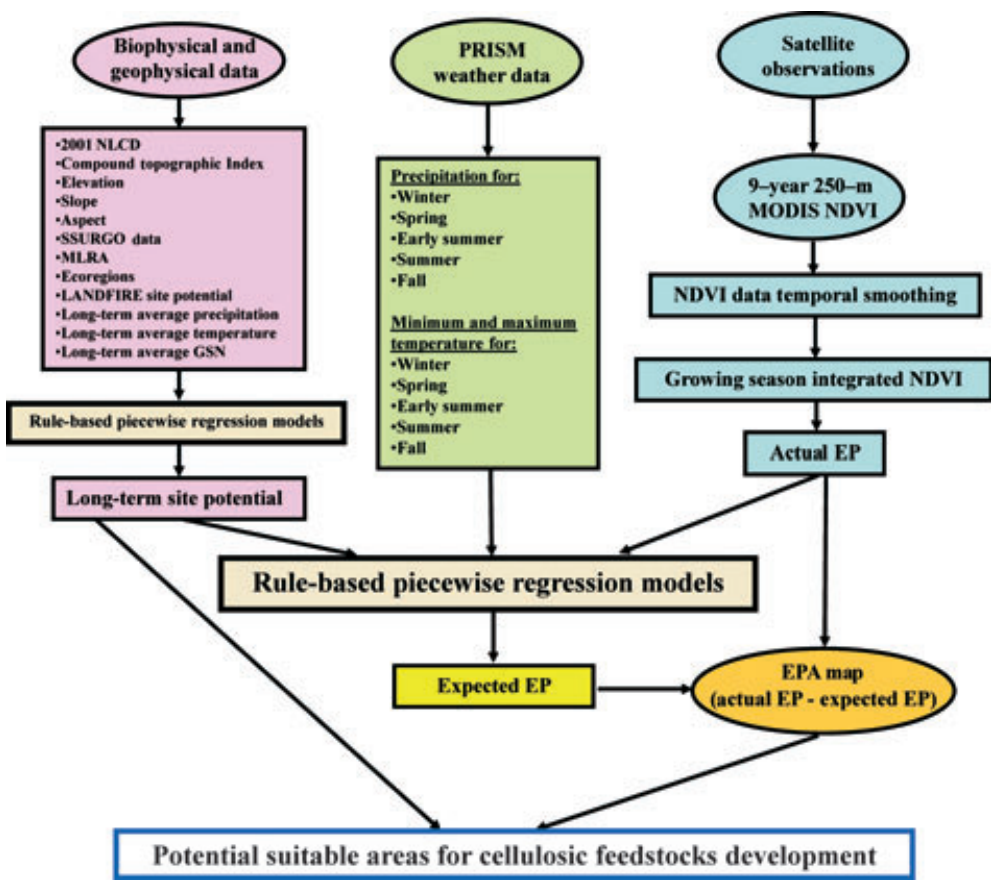

Fig. 4 Flowchart for mapping suitable regions for cellulosic feedstocks based on the satellite observations, climate data, and ecosystem performance models.

1 Extracting grassland pixels within the study area using National Land Cover Database (NLCD) 2001 (Homer et al., 2004).

2 Calculating the actual EP for 2000-2008 using high quality (mask out 'cloud' and 'fill value' pixels) and temporally smoothed (reduce additional atmospheric noise) 7 -day $250 \mathrm{~m}$ eMODIS NDVI data (Swets et al., 1999; Jenkerson et al., 2010).

3 Estimating ecosystem site potential using rule-based piecewise regression modeling methods (using Cubist Software). Cubist develops generalized rule sets, or piecewise regressions, from regression trees resulting in optimal multiple regression models which are constrained by data ranges of variables. Such machine learning models are optimal for complex and nonlinear relationships with large sample sizes (Wylie et al., 2007). Data used for training rule-based piecewise regression modeling for calculating long-term site potential (Fig. 4) included (i) 9-year (2000-2008) averaged GSN derived from eMODIS NDVI; (ii) long-term (1971-2000) averaged precipitation, maximum temperature, and minimum temperature derived from the PRISM (Parameter-elevation Regressions on Independent Slopes Model) database (PRISM Climate Group); (iii) soil organic carbon (SOC) (which is related to soil texture and vegetation conditions) derived from the U.S. Department of Agriculture (USDA) Natural Resources Conservation Service (NRCS) Soil Survey Geographic (SSURGO) Database; (iv) USGS compound topographic index (CTI) and digital elevation model (DEM); (v) LANDFIRE environmental site potential data derived from the USGS national LANDFIRE project; (vi) north and south aspect and slope maps derived from the USGS DEM data; and (vii) Olson's Ecoregions map (Olson et al., 2001). The $4 \mathrm{~km}$ spatial resolution PRISM data and the $30 \mathrm{~m}$ data (e.g., CTI, DEM) were resampled to

Table 2 Attribute usage in the rule-based piecewise regression models for long-term site potential calculation

\begin{tabular}{llc}
\hline Name & $\begin{array}{l}\text { Usage in } \\
\text { conditions (\%) }\end{array}$ & $\begin{array}{l}\text { Usage in } \\
\text { model (\%) }\end{array}$ \\
\hline Annual precipitation & 88 & 99 \\
Mean annual maximum & 68 & 79 \\
$\quad$ temperature & & \\
SSURGO SOC data & 62 & 79 \\
DEM & 51 & 84 \\
Landfire site potential & 47 & N/A \\
Ecoregion & 26 & N/A \\
Mean annual minimum & 8 & 70 \\
temperature & & 45 \\
North slope and aspect & 3 & 14 \\
CTI & 1 & 15 \\
South slope and aspect & 0 & \\
\hline
\end{tabular}

CTI, compound topographic index; DEM, digital elevation model; SOC, soil organic carbon; SSURGO, Soil Survey Geographic. 
$250 \mathrm{~m}$ resolution using bilinear interpolation (downscaling) or spatial averaging (upscaling) to match the $250 \mathrm{~m}$ eMODIS NDVI data. Table 2 gives the attribute usage of the above parameters used in the rule-based piecewise regression models for long-term site potential calculation. Long-term climate conditions, elevation, and SOC are important variables for site potential calculation (Table 2).

4 Computing the EEP for 2000-2008 using a piecewise regression model (using Cubist Software) based on the site potential and the 2000-2008 seasonal weather data. Data used for training the rule-based piecewise regression models to calculate the EEP (Fig. 4) were: (i) 2000-2008 PRISM datasets (maximum and minimum temperature and precipitation) for winter (November-February), spring (March-April), early summer (May-June), summer (July-August), and fall (September-October); (ii) long-term ecosystem site potential; and (iii) 2000-2008 eMODIS GSN data. We separated the yearly weather data (with monthly stacks) into five seasonal-averaged weather data to (i) reduce the number of variables used in the Cubist model and (ii) capture the interannual weather variation impacts on the EEP. The final piecewise regression model had an overall training accuracy of $93 \%$ on 16231 observations. Table 3 is the attribute usage in the rule-based piecewise regression models for the EEP calculation. Ecosystem site potential and seasonal

Table 3 Attribute usage in the rule-based piecewise regression modeling for the expected ecosystem performance (EEP) calculation.

\begin{tabular}{llc}
\hline Name & $\begin{array}{l}\text { Usage in } \\
\text { conditions }(\%)\end{array}$ & $\begin{array}{l}\text { Usage in } \\
\text { model }(\%)\end{array}$ \\
\hline $\begin{array}{l}\text { Mean maximum temperature } \\
\left.\text { ( } T_{\text {max }}\right) \text { in winter }\end{array}$ & 67 & 81 \\
Ecosystem site potential & 62 & 100 \\
Mean precipitation $\left(P_{\mathrm{pt}}\right)$ & 53 & 89 \\
$\quad$ in early summer & & \\
Mean minimum temperature & 30 & 67 \\
$\quad\left(T_{\min }\right)$ in spring & & \\
$P_{\mathrm{pt}}$ in summer & 19 & 81 \\
$P_{\mathrm{pt}}$ in spring & 14 & 83 \\
$P_{\mathrm{pt}}$ in winter & 13 & 38 \\
$T_{\max }$ in early summer & 12 & 38 \\
$T_{\max }$ in summer & 5 & 44 \\
$T_{\max }$ in fall & 4 & 67 \\
$P_{\mathrm{pt}}$ in fall & 4 & 31 \\
$T_{\min }$ in fall & 3 & 60 \\
$T_{\min }$ in summer & 2 & 64 \\
$T_{\max }$ in spring & 2 & 45 \\
$T_{\min }$ in early summer & 0 & 57 \\
$T_{\min }$ in winter & 0 & 40 \\
\hline
\end{tabular}

weather conditions are important variables for the EEP calculation (Table 3 ).

5 Determining EP anomalies (the actual EP minus the EEP) for 2000-2008. The EPA maps are categorized as normal performance, underperformance, and overperformance (observed performance relative to weatherbased predictions) at the $90 \%$ confidence levels.

6 Mapping the multiyear (i.e., more than 7 years) grassland persistent ecosystem overperformance and underperformance (using the $80 \%$ confidence levels) for 2000-2008 (Wylie et al., 2008; Gu \& Wylie, 2010).

7 Identifying pixels that either overperformed or normally performed for more than 7 years during 20002008 and have moderate or high site potential. These pixels are potentially suitable for switchgrass expansion and development. Long-term climate conditions, elevation, SOC, and yearly seasonal precipitation and temperature are the most important performance variables (Tables 1 and 2) to determine these pixels.

8 Identifying areas that are vulnerable to ecological disturbance (i.e., sensitive to the environmental change) using soil condition data [i.e., SSURGO available water capacity (AWC) data]. These areas will be excluded from the suitable regions (detailed explanations are in the 'Discussion' section).

\section{Results}

Correlation between satellite-derived growing season averaged NDVI and flux tower growing season averaged GPP

Figure 5 is the scatter plot of the eMODIS GSN and the flux tower growing season averaged GPP. There is a strong relationship $\left(R^{2}=0.75\right)$ between the eMODIS

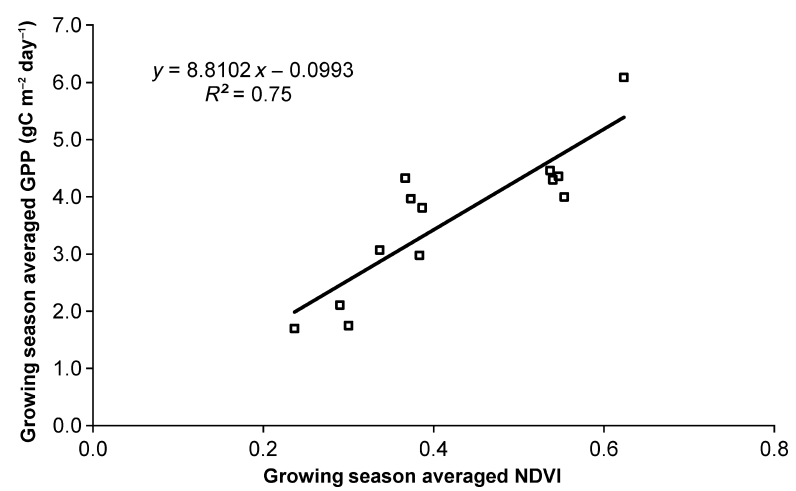

Fig. 5 Relationship between eMODIS GSN and the flux tower gross primary productivity (GPP) in the GPRB. Yearly growing season averaged GPP data (2000-2002 and 2005-2007) were collected from seven flux towers around the GPRB region. The yearly GSN data were also extracted for each $250 \mathrm{~m}$ pixel that geographically corresponded to each flux tower site. 
GSN and the flux tower growing season averaged GPP (Fig. 5). This result demonstrates that our approach used in this study (i.e., using GSN as a proxy for EP) is appropriate and reliable.

\section{Ecosystem site potential, actual EP, EEP, and EPA maps} for the GPRB

We selected EP results from one of the 9 years (2006) as an example for illustration and discussion purposes.
Figure 6 illustrates maps of (i) site potential, (ii) 2006 actual EP, (iii) $2006 \mathrm{EEP}$, and (vi) 2006 EPA for grasslands in the GPRB. The spatial distributions and the quantities of grassland site potential, actual EP, and the weather-based EEP in 2006 are shown in Fig. 6a-c. Areas with high grassland site potentials (Fig. 6a) could be suitable for cellulosic feedstocks expansion. Pixels that either overperformed or underperformed for 2006 are identified as green-blue and red-pink in Fig. 6d.

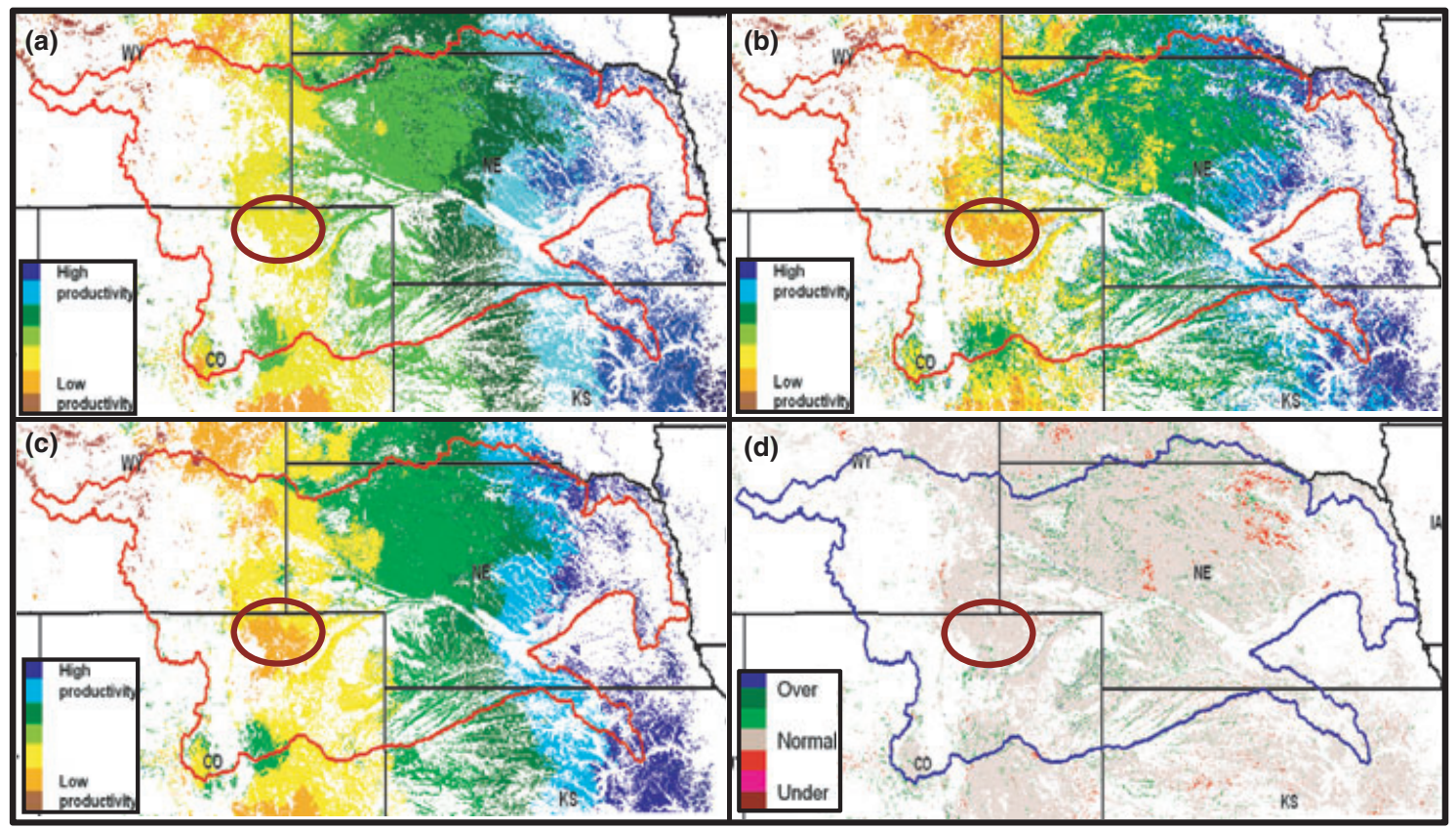

Fig. 6 Examples of site potential map, the actual EP map, the EEP map, and the EPA map for grassland in the Greater Platte River Basin (pixel size 250 m). (a) Site potential map; (b) 2006 actual EP map; (c) 2006 EEP map; (d) 2006 EPA map in which green-blue areas represent overperformance and red-pink areas represent underperformance. The area in the red outline is discussed in the text.

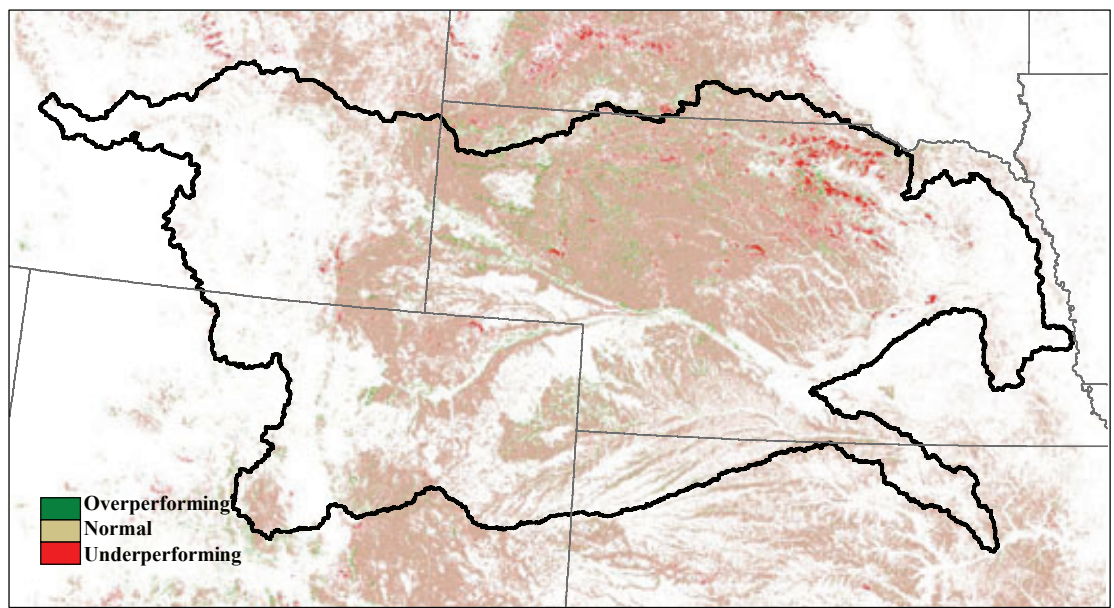

Fig. 7 Multiyear (i.e., more than 7 years) persistent EPA map for 2000-2008 in the GPRB (pixel size 250 m). Pixels persistently overperforming and underperforming are in green and red, respectively. 
Multiyear persistent EPA map for grassland in the GPRB

Figure 7 is the 2000-2008 multiyear persistent EPA map for grassland in the GPRB. Pixels that overperformed (underperformed) for 7 or more years are displayed in green (red). Pixels identified as overperforming or normal performing for multiple years (e.g., with less persistent ecological disturbances) are potentially suitable for cellulosic feedstock (e.g., switchgrass) expansion and development.

\section{Identification of regions suitable for cellulosic feedstock development}

To consider the influences caused by both site potential and the multiyear persistent EPA, pixels that either overperformed or normally performed for 7 (or more) of 9 years from 2000 to 2008 and have moderate or high site potential are identified in Fig. 8a. The resulting map shows that only a few regions potentially suitable for cellulosic feedstock development are located in the western and central parts of the GPRB. This is because unfavorable vegetation growth conditions existed in the western and central parts of the GPRB (see more details in the 'Discussion' section). Areas identified as suitable places for cellulosic feedstock (e.g., switchgrass) expansion are mainly located in the eastern section of the GPRB (Fig. 8a in green and blue colors).

\section{Discussion}

\section{Spatial variations of site potential, EP, and actual EP within the GPRB}

Site potential (i.e., long-term grassland productivity) gradually increases from west to east within the GPRB,

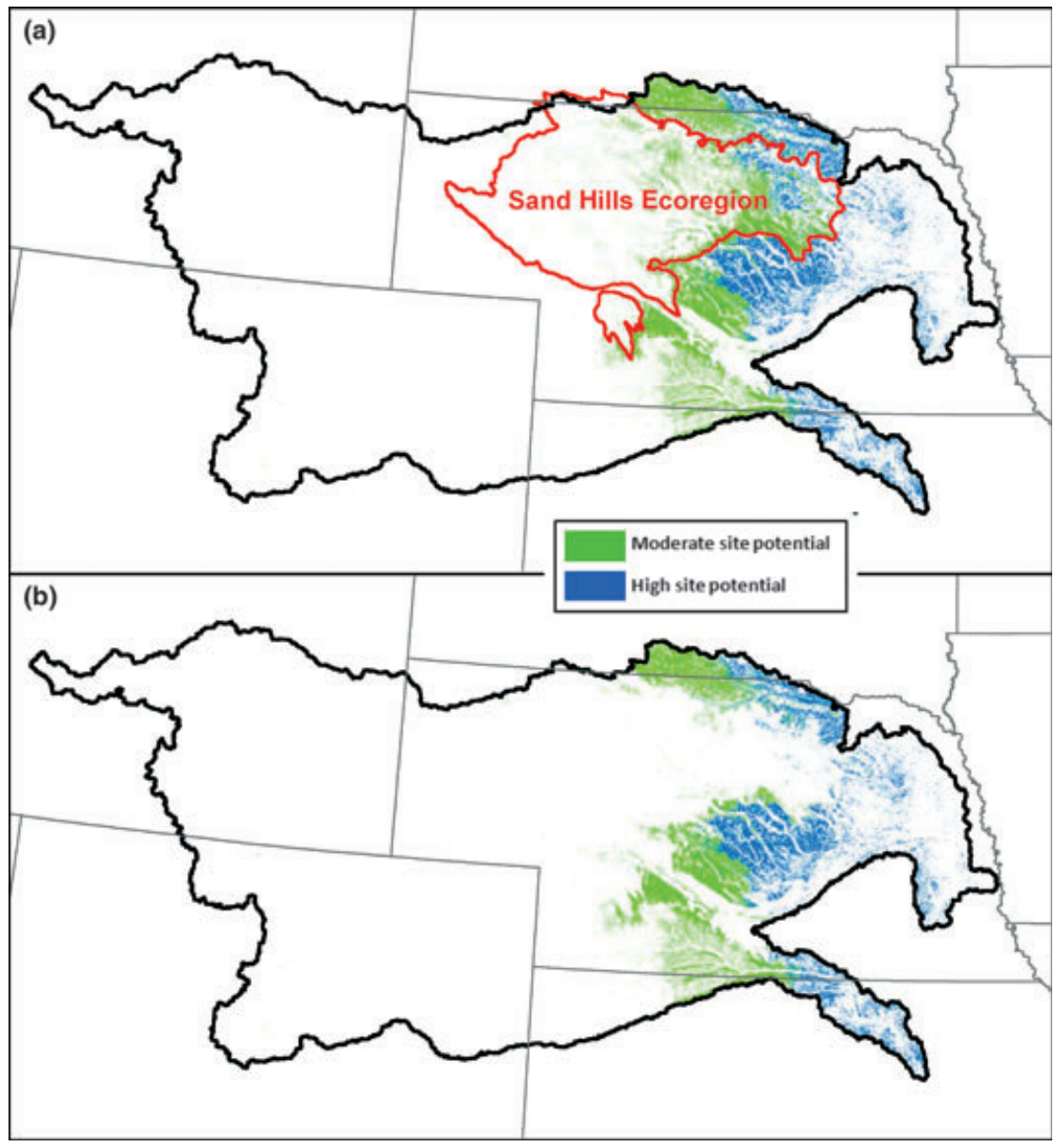

Fig. 8 (a) Map delineating potential suitable areas (green and blue) for cellulosic feedstock development within the GPRB. The Sand Hills ecoregion is shown with red outlines. (b) Final map delineating potentially suitable areas for cellulosic feedstock development within the GPRB and excluding the sandy areas within the Sand Hills ecoregion. Pixels in green and blue represent areas that either overperformed or normally performed for 7 of 9 years from 2000 to 2008 and with moderate (or high) site potential. The spatial resolutions for the two maps are $250 \mathrm{~m}$. 
as shown in Fig. 6a. These increases can be explained by different soil types, topography (mainly elevation), and climate conditions. The western part of the GPRB (southeastern Wyoming and northeastern Colorado) has very low site potential because of the unfavorable vegetation growth conditions (e.g., shallow or rocky soils, elevation is higher than $1500 \mathrm{~m}$, and low precipitation). On the other hand, the eastern part of the GPRB has high site potential because of the favorable vegetation growth conditions (e.g., good soil and climate conditions).

The general spatial patterns in the site potential map, the 2006 EP map, and the 2006 weather-based EEP map (Fig. 6a-c) are similar (e.g., productivities increase from west to east), but there are many differences among these three maps because of the ecological disturbances and the weather conditions. For example, both actual EP and EEP (for 2006) are significantly lower than site potential within the area outlined in dark red (Fig. $6 \mathrm{a}-\mathrm{c}$ ). The reason for these low actual EP and EEP was the extreme drought condition that occurred in northeastern Colorado (within the dark red outline) during 2006 (U.S. Drought Monitor Data Archives, 2006). Extreme drought led to low grassland productivities for both actual EP and the weather-based EEP in 2006. This approach clearly identified the extreme drought that occurred in northeastern Colorado during 2006, demonstrating the ability of this modeling approach to define performance.

Furthermore, although the actual EP in 2006 was much lower than the normal site potential within the area outlined in dark red (Fig. 6b) because of the extreme drought condition, the EP anomalies (the difference between the actual EP and the weather-based EEP) for 2006 in the same area still indicated normal performance or overperformance (Fig. 6d). Even though there was an extreme drought condition in 2006 (e.g., very low precipitation), our model produced low weatherbased EEP for 2006 and led to the ecosystem normal performance or overperformance shown in the area outlined in dark red. This demonstrates that our approach can successfully separate the weather-related (e.g., drought) and the ecological disturbance-related (e.g., wildfires, floods, insects, and overgrazing) annual EP variations, which can help identify the potential causes of ecosystem variations and can help guide best management practices.

\section{Identification of areas vulnerable to ecological disturbance}

The map in Fig. 8a shows that some areas identified as suitable for cellulosic feedstock expansion are located within the Sand Hills ecoregion (within the red outlines in Fig. 8a). Because of the special biophysical, geophysical, and biogeochemical characteristics of the Sand Hills ecoregion (e.g., sand dune systems, sandy soil, native grassland, and semiarid climate conditions) (Sand Hills Ecoregion, National Geographic) and to avoid any undesirable land use and land cover changes, we suggest that some areas within the Sand Hills ecoregion probably are not suitable for switchgrass development or other intensive agriculture practices (removal of biomass may lead to sand dune activation). Accordingly, SSURGO AWC data, which represents the amount of water that can be stored in soil and is available for use by plants (USDA Natural Resources Conservation Service, 1998), was used to identify sandy soil within the Sand Hills ecoregion in this study. Areas with very low AWC (less than $10 \mathrm{~cm}$ ) within the Sand Hills ecoregion were identified and were considered as sandy soils, which are not suitable for cellulosic feedstock development or other intensive agriculture practices. These areas were excluded from Fig. $8 \mathrm{~b}$, which is the final map delineating potential suitable areas (green and blue) for cellulosic feedstock development. The total suitable area for cellulosic feedstock development within the grasslands of the GPRB is ca. $68000 \mathrm{~km}^{2}$.

The spatial patterns of the potential grasslands that could be used for cellulosic feedstock production derived in this study generally agree with the previous modeling results (e.g., Thomson et al., 2009) and results based on county statistics (Milbrandt, 2005). Our analyses focus on biofuel expansion into productive grasslands which would minimize the impacts on food production. The advantage of this approach is to use a long-term satellite data archive (2000-2008 eMODIS data) which enables modeling with a reasonable spatial resolution $(250 \mathrm{~m}$, which can provide site specific information about suitability), and the dynamic modeling of EP method which is data driven and based on large sample sizes to identify the suitable areas.

\section{Conclusions}

This study identified grasslands potentially suitable for cellulosic feedstock (e.g., switchgrass) development within the GPRB using satellite observations, weather and climate data, and EP models. Areas with high and moderate ecosystem site potential and persistent ecosystem overperformance and normal performance are identified. The resulting map delineating areas suitable for cellulosic feedstock development within the GPRB (ca. $68000 \mathrm{~km}^{2}$ ) is potentially useful to land managers, decision makers, and biogeochemical modelers to make optimal land use decisions for cellulosic feedstock development and sustainability.

This study demonstrates the capability of using satellite observations to identify areas potentially suitable for switchgrass or other feedstock cultivation. It reveals the broad usage and the wide application of 
the satellite remote sensing data. This research represents the first step in identifying grassland areas suitable for cellulosic feedstock development. In future studies, we will investigate how economic considerations (e.g., the minimum region required to support a cellulosic refiner, transportation costs, etc.) influence the suitable areas, especially for small or isolated areas within the GPRB. We will evaluate the environmental and climate impacts (e.g., carbon sequestration, soil, and land cover changes) caused by potential cellulosic feedstock expansion and development in the suitable regions. We also plan to validate the results derived from this study using ground observations and extend these methods to the other geographic regions (e.g., the Central Great Plains).

\section{Acknowledgements}

This work was performed under USGS contracts G08PC91508 and G10PC00044, and funded by the USGS Geographic Analysis and Monitoring Program in support of Renewable EnergyBiofuels initiative. The authors thank Norman Bliss for processing and providing SSURGO soil organic carbon (SOC) data. The authors thank Norman Bliss, Bhaskar Ramachandran, and Thomas Adamson for their valuable suggestions and comments. Any use of trade, product, or firm names is for descriptive purposes only and does not imply endorsement by the US Government.

\section{References}

Asner GP, Elmore AJ, Olander LP, Martin RE, Harris T (2004) Grazing systems, ecosystem responses, and global change. Annual Review of Environment and Resources, 29, 261-299.

Becker-Reshef I, Vermote E, Lindeman M, Justice C (2010) A generalized regression-based model for forecasting winter wheat yields in Kansas and Ukraine using MODIS data. Remote Sensing of Environment, 114, 1312-1323.

Blanco-Canqui H (2010) Energy crops and their implications on soil and environment. Agronomy Journal, 102, 403-419.

Bracmort K (2010) Meeting the Renewable Fuel Standard (RFS) mandate for cellulosic biofuels: questions and answers. CRS (Congressional Research Service) Report for Congress, Washington, DC, USA. RL41106.

Bracmort K, Schnepf R, Stubbs M, Yacobucci BD(2010) Cellulosic biofuels: analysis of policy issues for congress. CRS Report for Congress, Washington, DC, USA. RL34738.

Bunn AG, Goetz SJ, Fiske GJ (2005) Observed and predicted responses of plant growth to climate across Canada. Geophysical Research Letters, 32, 1-4.

Cubist Software (2009) RuleQuest Research Pty Ltd, NSW, Australia. Available at: http://www.rulequest.com (accessed 18 July 2009).

Dunn AL, Barford CC, Wofsy SC, Goulden ML, Daube BC (2007) A long-term record of carbon exchange in a boreal black spruce forest: means, responses to interannual variability, and decadal trends. Global Change Biology, 13, 577-590.
Funk C, Budde ME (2009) Phenologically-tuned MODIS NDVIbased production anomaly estimates for Zimbabwe. Remote Sensing of Environment, 113, 115-125.

Gelfand I, Snapp SS, Robertson GP (2010) Energy efficiency of conventional, organic, and alternative cropping systems for food and fuel at a site in the U.S. Midwest. Environmental Science \& Technology, 44, 4006-4011.

Gitelson AA, Viña A, Verma SB, et al. (2006) Relationship between gross primary production and chlorophyll content in crops: implications for the synoptic monitoring of vegetation productivity. Journal of Geophysical Research, 111, D08S11.

Gu Y, Wylie BK (2010) Detecting ecosystem performance anomalies for land management in the Upper Colorado River Basin using satellite observations, climate data, and ecosystem models. Remote Sensing, 2, 1880-1891.

Guretzky JA, Biermacher JT, Cook BJ, Kering MK, Mosali J (2011) Switchgrass for forage and bioenergy: harvest and nitrogen rate effects on biomass yields and nutrient composition. Plant and Soil, 339, 69-81.

Hobbs TJ (1995) The use of NOAA-AVHRR NDVI data to assess herbage production in the arid rangelands of central Australia. International Journal of Remote Sensing, 16, 1289-1302.

Homer C, Huang C, Yang L, Wylie B, Coan M (2004) Development of a 2001 National Land-Cover Database for the United States. Photogrammetric Engineering and Remote Sensing, 70, 829-840.

Jenkerson CB, Maiersperger TK, Schmidt GL (2010) eMODIS a user-friendly data source. U.S. Geological Survey (USGS) Open-File Report, Reston, VA, USA. 2010-1055.

Kang S, Kimball JS, Running SW (2006) Simulating effects of fire disturbance and climate change on boreal forest productivity and evapotranspiration. Science of the Total Environment, 362, 85-102.

Kimball JS, Zhao M, Mcdonald KC, Running SW (2006) Satellite remote sensing of terrestrial net primary production for the pan-Arctic basin and Alaska. Mitigation and Adaptation Strategies for Global Change, 11, 783-804.

Launchbaugh K, Brammer B, Brooks ML et al. (2008) Interactions among livestock grazing, vegetation type, and fire behavior in the Murphy Wildland Fire Complex in Idaho and Nevada, July 2007. USGS Open-File Report, Reston, VA, USA. 2008-1214.

Liebig MA (2006) USDA and DOE favor switchgrass for biomass fuel. Industrial Bioprocessing, 28, 7.

Liebig MA, Schmer MR, Vogel KP, Mitchell RB (2008) Soil carbon storage by switchgrass grown for bioenergy. Bioenergy Research, 1, 215-222.

Mclaughlin SB, Kszos LA (2005) Development of switchgrass (Panicum virgatum) as a bioenergy feedstock in the United States. Biomass and Bioenergy, 28, 515-535.

Milbrandt A (2005) A geographic perspective on the current biomass resource availability in the United States, TP-560-39181, National Renewable Energy Laboratory (NREL), Golden, CO, USA.

Olson DM, Dinerstein E, Wikramanayake ED, et al. (2001) Terrestrial ecoregions of the world: a new map of life on Earth. BioScience, 51, 933-938.

Pala C (2010) Study finds using food grain to make ethanol is energy-inefficient. Environmental Science \& Technology, 44, 3648. 
Pimentel D (2010) Corn and cellulosic etanol problems and soil erosion. In: Soil quality and biofuel production (ed. Lal R, Stewart BA), pp. 119-135. CRC Press, Taylor\&Francis Group, Boca Raton, FL, USA.

PRISM Climate Group, Oregon State University. Available at: http:/ / www.prismclimate.org (accessed 1 March 2010).

Rupp TS, Chapin FS III, Starfield AM (2000) Response of subarctic vegetation to transient climatic change on the Seward Peninsula in north-west Alaska. Global Change Biology, 6, 541-555.

Sand Hills Ecoregion, National Geographic. Nebraska Sand Hills mixed grasslands. Available at: http://www.nationalgeographic.com/wildworld/profiles/terrestrial/na/na0809.html (accessed 21 January 2011).

Sanderson MA, Adler PR, Boateng AA, Casler MD, Sarath G (2006) Switchgrass as a biofuels feedstock in the USA. Canadian Journal of Plant Science, 86, 1315-1325.

Saxon E, Baker B, Hargrove W, Hoffman F, Zganjar C (2005) Mapping environments at risk under different global climate change scenarios. Ecology Letters, 8, 53-60.

Schmer MR, Vogel KP, Mitchell RB, Perrin RK (2008) Net energy of cellulosic ethanol from switchgrass. Proceedings of the National Academy of Sciences of the United States of America, 105, 464-469.

Schmer MR, Mitchell RB, Vogel KP, Schacht WH, Marx DB (2010) Spatial and temporal effects on switchgrass stands and yield in the Great Plains. Bioenergy Research, 3, 159-171.

Schnepf R, Yacobucci BD (2010) Selected issues related to an expansion of the Renewable Fuel Standard (RFS). CRS Report for Congress, Washington, DC, USA. R40155.

Simpson T (2009) Biofuels: the past, present, and a new vision for the future. BioScience, 59, 926-927.

Solomon BD, Barnes JR, Halvorsen KE (2007) Grain and cellulosic ethanol: history, economics, and energy policy. Biomass and Bioenergy, 31, 416-425.

Swets DL, Reed BC, Rowland JR, Marko SE(1999) A weighted least-squares approach to temporal smoothing of NDVI. ASPRS Annual Conference, From Image to Information, Portland, OR, USA.

Thomson AM, Izarrualde RC, West TO, Parrish DJ, Tyler DD, Williams JR (2009). Simulating potential switchgrass production in the United States, Pacific Northwest National Laboratory, Richland, WA, USA. PNNL-19072.

Tieszen LL, Reed BC, Bliss NB, Wylie BK, Dejong DD (1997) NDVI, $C_{3}$ AND $C_{4}$ production, and distributions in Great Plains grassland land cover classes. Ecological Applications, 7, 59-78.

Trostle R (2008) Global agricultural supply and demand: factors contributing to the recent increase in food commodity prices. Eco- nomic Research Service, WRS-0801. US Department of Agriculture, Washington, DC, USA.

Tucker CJ, Vanpraet CL, Sharman MJ, Van Ittersum G (1985) Satellite remote sensing of total herbaceous biomass production in the Senegalese Sahel: 1980-1984. Remote Sensing of Environment, 17, 233-249.

U.S. Drought Monitor Data Archives (2006). Available at: http://drought.unl.edu/dm/archive.html (accessed 20 October 2010).

USDA Natural Resources Conservation Service. 1998. Soil Quality Information Sheet, Soil Quality Resource Concerns: Available Water Capacity. Available at: http://soils.usda.gov/sqi/pub lications/files/avwater.pdf (accessed 21 January 2011).

USGS Digital Elevation Model data. Available at: http://eros. usgs.gov/\#Find_Data/Products_and_Data_Available/DEMs (accessed 20 March 2010).

USGS LANDFIRE Data (2009) LANDFIRE Data Distribution Site. Available at http://landfire.cr.usgs.gov/viewer/ (accessed 20 June 2009).

Vadas PA, Barnett KH, Undersander DJ (2008) Economics and energy of ethanol production from alfalfa, corn, and switchgrass in the Upper Midwest, USA. Bioenergy Research, 1, 44-55.

Viereck LA, Van Cleve K, Dyrness CT (1984) Some aspects of vegetation and temperature relationships in the Alaska taiga. In: The Potential Effects of Carbon-dioxide-Induced Climate Changes In Alaska (ed. Mcbeath JH), pp. 129-142. University of Alaska, Fairbanks, AK, USA.

Viereck LA, Dyrness CT, Batten AR, Wenzlick KJ (1992) The Alaskan vegetation classification. USDA Pacific Northwest Research Station General Technical Report, Portland, OR, USA. PNW-GTR-286.

Wang Q, Adiku S, Tenhunen J, Granier A (2005) On the relationship of NDVI with leaf area index in a deciduous forest site. Remote Sensing of Environment, 94, 244-255.

White AB, Kumar P, Tcheng D (2005) A data mining approach for understanding topographic control on climate-induced inter-annual vegetation variability over the United States. Remote Sensing of Environment, 98, 1-20.

Wylie BK, Fosnight EA, Gilmanov TG, Frank AB, Morgan JA, Haferkamp MR, Meyers TP (2007) Adaptive data-driven models for estimating carbon fluxes in the northern Great Plains. Remote Sensing of Environment, 106, 399-413.

Wylie BK, Zhang L, Bliss NB, Ji L, Tieszen LL, Jolly WM (2008) Integrating modelling and remote sensing to identify ecosystem performance anomalies in the boreal forest, Yukon River Basin, Alaska. International Journal of Digital Earth, 1, 196-220.

Zhang L, Wylie BK, Ji L, Gilmanov TG, Tieszen LL (2010) Climate-driven interannual variability in net ecosystem exchange in the northern Great Plains grasslands. Rangeland Ecology and Management, 63, 40-50. 